\title{
DL0805-2, a novel indazole derivative, relaxes angiotensin II-induced contractions of rat aortic rings by inhibiting Rho kinase and calcium fluxes
}

\author{
Tian-yi YUAN ${ }^{1,2}$, Yu-cai CHEN ${ }^{1,2}$, Hui-fang ZHANG ${ }^{1,2}$, Li LI ${ }^{2}$, Xiao-zhen $J_{A O}^{1}$, Ping XIE ${ }^{1}$, Lian-hua FANG ${ }^{2, *}$, Guan-hua DU ${ }^{1,2, *}$

\begin{abstract}
${ }^{1}$ State Key Laboratory of Bioactive Substances and Functions of Natural Medicines, Institute of Materia Medica, Chinese Academy of Medical Sciences and Peking Union Medical College, Beijing 100050, China; ${ }^{2}$ Beijing Key Laboratory of Drug Targets Identification and Drug Screening, Institute of Materia Medica, Chinese Academy of Medical Sciences and Peking Union Medical College, Beijing 100050, China
\end{abstract}

Aim: DL0805-2 [N-(1H-indazol-5-yl)-1-(4-methylbenzyl) pyrrolidine-3-carboxamide] is a DL0805 derivative with more potent vasorelaxant activity and lower toxicity. This study was conducted to investigate the vasorelaxant mechanisms of DL0805-2 on angiotensin II (Ang II)induced contractions of rat thoracic aortic rings in vitro.

Methods: Rat thoracic aortic rings and rat aortic vascular smooth muscle cells (VSMCs) were pretreated with DL0805-2, and then stimulated with Ang II. The tension of the aortic rings was measured through an isometric force transducer. Ang II-induced protein phosphorylation, ROS production and F-actin formation were assessed with Western blotting and immunofluorescence assays. Intracellular free $\mathrm{Ca}^{2+}$ concentrations were detected with Fluo-3 AM.

Results: Pretreatment with DL0805-2 (1-100 $\mu \mathrm{mol} / \mathrm{L})$ dose-dependently inhibited the constrictions of the aortic rings induced by a single dose of Ang II $\left(10^{-7} \mathrm{~mol} / \mathrm{L}\right)$ or accumulative addition of Ang II $\left(10^{-10}-10^{-7} \mathrm{~mol} / \mathrm{L}\right)$. The vasodilatory effect of DL0805-2 was independent of endothelium. In the aortic rings, pretreatment with DL0805-2 (1, 3, and $10 \mu \mathrm{mol} / \mathrm{L})$ suppressed Ang II-induced $\mathrm{Ca}^{2+}$ influx and intracellular $\mathrm{Ca}^{2+}$ mobilization, and Ang Il-induced phosphorylation of two substrates of Rho kinase (MLC and MYPT1). In VSMCs, pretreatment with DL0805-2 (1, 3, and $10 \mu \mathrm{mol} / \mathrm{L})$ also suppressed Ang Il-induced $\mathrm{Ca}^{2+}$ fluxes and phosphorylation of MLC and MYPT1. In addition, pretreatment with DL0805-2 attenuated ROS production and F-actin formation in the cells.

Conclusion: DL0805-2 exerts a vasodilatory action in rat aortic rings through inhibiting the Rho/ROCK pathway and calcium fluxes.

Keywords: DL0805-2; angiotensin Il; vasorelaxation; Rho/ROCKs; $\mathrm{Ca}^{2+}$ fluxes; rat aortic ring; vascular smooth muscle cells

Acta Pharmacologica Sinica (2016) 37: 604-616; doi: 10.1038/aps.2015.161; published online 4 Apr 2016

\section{Introduction}

Hypertension is a global health crisis that has influenced over one billion people worldwide. It is also one of the key factors for cardiovascular diseases and may further result in heart attack, stroke, kidney failure and even disability or death ${ }^{[1]}$. Although there are many anti-hypertensive drugs that are used clinically, the development of new medications for the treatment of hypertension is in high demand. Efforts have been pursued by our team for several years to identify novel anti-hypertensive small molecular compounds with vasodila-

\footnotetext{
* To whom correspondence should be addressed.

E-mail fanglh@imm.ac.cn (Lian-hua FANG); dugh@imm.ac.cn (Guan-hua DU).

Received 2015-10-18 Accepted 2015-12-25
}

tory activity.

In recent basic and clinical studies, the Rho kinases (ROCKs) have been identified as important targets potentially involved in a variety of cardiovascular diseases including hypertension $^{[2,3]}$. As important effectors of the small $G$ proteins, the ROCKs have been found to participate in a wide range of fundamental cellular functions, such as cell morphology, motility, contraction, adhesion, migration, proliferation, differentiation, and apoptosis ${ }^{[4-6]}$. Abnormalities in the Rho/ROCK pathway have been observed in various cardiovascular diseases, especially hypertension ${ }^{[7,8]}$.

Calcium channel blockers are widely used in the treatment of hypertension, and this class of drugs is one of the most classical ones used in clinics ${ }^{[9]}$. The inhibition of voltage-operated or receptor-operated calcium channels will decrease intracel- 
lular $\mathrm{Ca}^{2+}$ concentration and relax the contraction of vessels to relieve vascular spasms ${ }^{[10-12]}$. Discovering novel Rho kinase inhibitors that simultaneously block calcium fluxes might be a promising way to develop new anti-hypertension drugs.

DL0805 (5-nitro-1H-indazole-3-carbonitrile) is a new Rho kinase inhibitor discovered by high-throughput screening (HTS) during our previous work, and was also found to have a vasorelaxant effect ${ }^{[13,14]}$. After further study, it was found to have high toxicity, which hindered its development. Through sustained designing and structure modification to DL0805 by our collaborating laboratory, several compounds bearing an indazole scaffold were obtained and were found to achieve a good effect on cardiovascular protection in vitro. Among these compounds, a new chemical entity, DL0805-2 ( N-(1Hindazol-5-yl)-1-(4-methylbenzyl) pyrrolidine-3-carboxamide) exhibits a much stronger vasorelaxant effect than all of the other compounds including DL0805. Moreover, its toxicity is much lower. We have reported the vasodilatory effect of DL0805-2 on the peripheral arteries of rats ${ }^{[15]}$, while its action in large vessels has not been investigated. As is well known, large vessels, especially thoracic aortas, are also important in the development of hypertension. Considering that DL0805-2 is a totally new structure that has not been reported by other laboratories, it is of great interest to explore its medical value and its potency as a drug candidate. Therefore, in the present study, we investigated the effects of DL0805-2 on rat thoracic aortas and vascular smooth muscle cells (VSMCs) that were stimulated by a crucial vasoconstrictor, angiotensin II (Ang II), and elucidated its possible mechanisms. The inhibition of the Rho/ROCK pathway and blockage of calcium fluxes will be the major concerns.

\section{Materials and methods}

\section{Materials}

DL0805-2 $\left(\mathrm{C}_{20} \mathrm{H}_{22} \mathrm{~N}_{4} \mathrm{O}, M_{\mathrm{W}}\right.$ : 334.42, Figure 1) was synthesized by the Department of Medicinal Chemistry Laboratory of our institute. The purity is greater than $99 \%$, and the structure has been confirmed by the analysis of physical-chemical properties and spectral evidence. The detailed synthesis and purification of this compound has been reported in a Chinese patent (Application № 2012101721910).

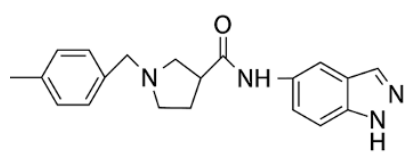

Figure 1. The chemical structure of DL0805-2; $\mathrm{N}$-(1H-indazol-5-yl)-1-(4methylbenzyl)pyrrolidine-3-carboxamide; $\mathrm{C}_{20} \mathrm{H}_{22} \mathrm{~N}_{4} \mathrm{O}, M_{\mathrm{w}}$ : 334.42.

The enzyme-linked immunosorbent assay (ELISA) kit for the Rho kinase activity assay was purchased from Cyclex (Nagano, Japan). Recombinant human activated ROCK1 was purchased from R \& D Systems Inc (Minneapolis, MN, USA). Norepinephrine $(\mathrm{NE})$, acetylcholine $(\mathrm{ACh})$ and angiotensin
II (Ang II) were purchased from Sigma (St Louis, MO, USA). Ethylene glycol tetraacetic acid (EGTA) was purchased from Amresco (Solon, OH, USA). The $\mathrm{Ca}^{2+}$ probe Fluo 3-AM was purchased from Dojindo (Kumamoto, Japan). Antibodies against phosphor-MYPT1 (Thr 696), total MYPT1 (myosin phosphatase target subunit 1), phosphor-MLC (Ser 19), total MLC (myosin light chain), phosphor-ERM (Ezrin/Radixin/ Moesin), phosphor-cofilin and Alexa Fluor 488 phalloidin were purchased from Cell Signaling Technology Inc (Beverly, MA, USA). Antibodies against GAPDH and phosphor-Limk were purchased from Santa Cruz Biotechnology Inc (Dallas, TX, USA). All other reagents were purchased domestically and met the experimental standards.

\section{Rho kinase activity assay}

The inhibitory effect of DL0805-2 on ROCK1 was detected by ELISA according to the instruction of the Rho kinase assay kit (CY-1160, Cyclex). In brief, DL0805-2 was pre-incubated in a system wherein ROCK1 $(0.02 \mathrm{ng} / \mu \mathrm{L})$ phosphorylates the kinase substrate myosin-binding subunit (MBS) pre-absorbed onto the microplate in the presence of $\mathrm{Mg}^{2+}$ and ATP. The phosphorylated form of threonine-696 on MBS can be recognized specifically by the detector antibody called AF20, which has been bound with horseradish peroxidase. Horseradish peroxidase catalyzes the conversion of the chromogenic substrate tetra-methylbenzidine (TMB) from a colorless solution to a blue solution. The absorbance at a wavelength of $450 \mathrm{~nm}$ is measured after adding $\mathrm{H}_{2} \mathrm{SO}_{4}$ to stop the reaction. The color reflects the relative level of ROCK1 activity in the sample. The values of $O D_{450 \mathrm{~nm}}$ were used to calculate the percent inhibition and nonlinear regression was used to obtain the $\mathrm{IC}_{50}$ value.

\section{Preparation and tension recording of rat aortic rings}

Male Sprague-Dawley rats weighing 240-280 g (60-70 days old) were provided by Vital River Laboratories, Beijing, China. The animals were housed in plastic cages under controlled humidity $(50 \%)$ and temperature $\left(25^{\circ} \mathrm{C}\right)$, and they were exposed to a $12 \mathrm{~h}$ light/dark cycle with free access to purified water and a standard diet. The animal care and handling were performed in accordance with the Guide for the Care and Use of Laboratory Animals published by the US National Institutes of Health and the Laboratories Institutional Animal Care and Use Committee of Chinese Academy of Medical Science and Peking Union Medical College.

The descending thoracic aorta was isolated rapidly after rats were euthanized by cervical dislocation. The adherent connective tissue was cleaned carefully, and then the aorta was cut into ring segments (3-4 $\mathrm{mm}$ in length). The endothelial layer of the aorta was destroyed by gently rubbing the luminal surface with a moist cotton swab as necessary. Two stainless steel triangles were passed through the lumen of each ring. One triangle was connected to an isometric force transducer connected to a BIOPAC polygraph (MP100WSW, Biopac Systems, Inc, Goleta, CA, USA) to measure tension in the vessels ${ }^{[16,17]}$. The rings were mounted in organ baths containing $10 \mathrm{~mL}$ Krebs-Henseleit (K-H) solution of the following composition 
(mmol/L): $\mathrm{NaCl} 120, \mathrm{KCl} 4.8, \mathrm{MgSO}_{4}$ 1.4, $\mathrm{KH}_{2} \mathrm{PO}_{4}$ 1.2, glucose 11.0, $\mathrm{CaCl}_{2} 2.5, \mathrm{NaHCO}_{3} 25.0$, and EDTA 0.01. The K-H solution was kept at $37^{\circ} \mathrm{C}$ and continuously bubbled with a $95 \% \mathrm{O}_{2} / 5 \% \mathrm{CO}_{2}$ gas mixture ${ }^{[18]}$. The aortic preparations were stretched until they reached a resting tension of $1.2 \mathrm{~g}$. Then, they were equilibrated for $60 \mathrm{~min}$; during this time, the bath fluid was changed every $20 \min ^{[19]}$.

After the equilibration period, the aortic rings were constricted with a high $\mathrm{K}^{+}(60 \mathrm{mmol} / \mathrm{L}) \mathrm{K}-\mathrm{H}$ solution to stimulate the tissue and to verify its availability. Then, the rings were washed with normal K-H solution to restore the basic tension of $1.2 \mathrm{~g}$. To confirm the integrity of the endothelium, acetylcholine $(10 \mu \mathrm{mol} / \mathrm{L})$ was added to the bath following stabilized contraction induced by NE $(1 \mu \mathrm{mol} / \mathrm{L})$. When the relaxant response to $\mathrm{ACh}$ was less than $10 \%$, the endothelium was considered to be completely removed. When the relaxant response was greater than $90 \%$, the endothelium was considered to be intact. Suitable aortic rings were chosen for the following experiments.

Subsequently, Ang II was used to stimulate the tension of the aortic rings. DL0805-2 were added to the organ bath, and the aortic rings were incubated with various concentrations of DL0805-2 for $30 \mathrm{~min}$. Then, a single dose of Ang II (100 $\mathrm{nmol} / \mathrm{L}$ ) was added to induce a transient vasoconstriction. In this experiment, both endothelium-intact and -denuded rings were used to verify the influence of the endothelium. In a separate experiment of endothelium-denuded aortic rings, Ang II ranging from $1 \times 10^{-10} \mathrm{~mol} / \mathrm{L}$ to $1 \times 10^{-7} \mathrm{~mol} / \mathrm{L}$ was applied cumulatively to obtain concentration-response curves. An interval time of $3 \mathrm{~min}$ was used to ensure that the next concentration of Ang II was added when the last maximum tension was obtained. In other experiments, $\mathrm{KCl}$ ranging from 10 to $60 \mathrm{mmol} / \mathrm{L}$ or NE ranging from $1 \times 10^{-9} \mathrm{~mol} / \mathrm{L}$ to $1 \times 10^{-6} \mathrm{~mol} / \mathrm{L}$ was applied cumulatively to obtain concentration-response curves. The interval time was $5 \mathrm{~min}$.

\section{Molecular docking}

A molecular model of a complex between [Sar1, Bpa8] Ang II and the hAT1 receptor was downloaded from the PDB (PDB entry: 1ZV0). The crystal structure of Rho kinase in complex with Y27632 (a Rho kinase inhibitor) was downloaded from the PDB (PDB entry: 2H9V). To obtain the docking-binding models for $\mathrm{AT}_{1} \mathrm{R}$ or Rho kinase in complex with DL0805-2, the molecular modeling program MOE 2010 (Chemical Computing Group Inc., Canada) was used to perform the docking process. The detailed parameter settings and the docking process was carried out as previously described ${ }^{[20]}$. Losartan (an Ang II receptor antagonist) and fasudil (a Rho kinase inhibitor) were used as positive controls.

\section{Calcium fluxes in isolated aortic rings}

Calcium fluxes in isolated aortic rings will cause changes in vascular tone. When the calcium concentration in the cytoplasm is elevated, the isolated aortic rings will contract. Through the elution of extracellular calcium and/or intracellular calcium, the inhibitory effect of DL0805-2 on calcium fluxes was observed. The extracellular calcium was eluted by $\mathrm{Ca}^{2+}$-free $\mathrm{K}-\mathrm{H}$ solution with $50 \mu \mathrm{mol} / \mathrm{L}$ EGTA. The aortic rings were incubated with 1,3 , and $10 \mu \mathrm{mol} / \mathrm{L}$ DL0805-2 for $30 \mathrm{~min}$, and then $1 \mu \mathrm{mol} / \mathrm{L}$ Ang II was added to cause the release of intracellular calcium. The transient contraction was recorded to reflect the level of $\mathrm{Ca}^{2+}$ release. To investigate the inhibitory effect of DL0805-2 on extracellular $\mathrm{Ca}^{2+}$ influx, both extracellular and intracellular calcium were eluted by $\mathrm{Ca}^{2+}$ free $\mathrm{K}-\mathrm{H}$ solution with $1 \mathrm{mmol} / \mathrm{L}$ EGTA. The aortic rings were incubated with 1, 3, and $10 \mu \mathrm{mol} / \mathrm{L}$ DL0805-2 for $20 \mathrm{~min}$, and then $1 \mu \mathrm{mol} / \mathrm{L}$ Ang II was added to the organ bath and co-incubated for $10 \mathrm{~min}$. Subsequently, a final concentration of $2.5 \mathrm{mmol} / \mathrm{L} \mathrm{CaCl}_{2}$ solution was added to the bath. The Ang II in the bath caused a $\mathrm{Ca}^{2+}$ influx into the smooth muscle cells and vasoconstriction. The vascular tone was recorded to reflect the extracellular calcium influx levels.

\section{Vascular smooth muscle cell culture}

Rat aortic vascular smooth muscle cells (VSMCs) were isolated from the thoracic aortas of male SD rats by enzymatic digestion and tissue explant method as previously described ${ }^{[21,22]}$. Cells were cultured in Dulbecco's modified Eagle's medium (DMEM) supplemented with 10\% (v/v) fetal bovine serum, $100 \mathrm{U} / \mathrm{mL}$ penicillin and $100 \mathrm{mg} / \mathrm{mL}$ streptomycin. The cells were incubated at $37^{\circ} \mathrm{C}$ in a $5 \% \mathrm{CO}_{2}$ humidified atmosphere. Cells were used at passages 4-8 and serum-starved for $24 \mathrm{~h}$ prior to exposure to the various treatments.

\section{Western blot assay}

Rat endothelium-denuded aortic rings were prepared as mentioned in part 2.3. The rings were pretreated with either DL0805-2 $(1,3,10$, and $30 \mu \mathrm{mol} / \mathrm{L})$ or an equal volume of solvent for $30 \mathrm{~min}$ prior to exposure to $1 \mu \mathrm{mol} / \mathrm{L} \mathrm{Ang} \mathrm{II} \mathrm{for}$ $4 \mathrm{~min}$, and then the rings were immediately frozen in liquid nitrogen.

VSMCs were pretreated with various concentrations of DL0805-2, from 0.03 to $10 \mu \mathrm{mol} / \mathrm{L}$, for $30 \mathrm{~min}$ prior to the addition of $1 \mu \mathrm{mol} / \mathrm{L}$ Ang II for $4 \mathrm{~min}$ and then washed with precooled PBS. In both experiments, fasudil was used as a positive control.

The aortic rings or cellular proteins were extracted using RIPA lysis buffer. After complete homogenization on ice, the samples were centrifuged. The supernatants were fractionated by $8 \%$ or $12 \%$ SDS-PAGE and then electro-transferred onto a PVDF membrane. The membranes were blocked with $5 \%$ BSA in Tris-buffered saline plus $0.1 \%$ Tween-20 (TBST) for $1 \mathrm{~h}$ at $37^{\circ} \mathrm{C}$. Then, they were subjected to an immunoblotting assay using primary antibodies to total MYPT1, phosphorMYPT1, total MLC, and phosphor-MLC as well as GAPDH as an internal reference.

\section{Immunofluorescent staining}

For immunofluorescent staining, rat VSMCs were cultured in black 96-well plates with a clear bottom (Corning Costar, NY, USA) at a density of 4000 or 10000 cells/well. Cells were starved for $24 \mathrm{~h}$ before the experiments. 
To detect F-actin formation, cells were pre-incubated with or without DL0805-2 (1, 3, and $10 \mu \mathrm{mol} / \mathrm{L})$ for $2 \mathrm{~h}$. Then, the cells were stimulated with $10^{-6} \mathrm{~mol} / \mathrm{L}$ Ang II for $4 \mathrm{~h}$, and $4 \%$ paraformaldehyde was used to fix the cells for $15 \mathrm{~min}$ at room temperature. After washing away the fixing buffer, the cells were treated with $0.1 \%$ Triton X-100/PBS for $15 \mathrm{~min}$ at $4^{\circ} \mathrm{C}$, blocked with $2 \%$ BSA/PBS for $1 \mathrm{~h}$ at room temperature, and then probed with Alexa Fluor 488 phalloidin for $20 \mathrm{~min}$ at room temperature in the dark. After washing out the extra dye, the cells were stained with Hoechst 33342 for 5 min $^{[23]}$.

To detect phosphorylation levels, cells were treated and handled as described above and as previously reported ${ }^{[24]}$. However, cells were stimulated with $10^{-6} \mathrm{~mol} / \mathrm{L}$ Ang II for only $3 \mathrm{~min}$ and then fixed with paraformaldehyde. After blockage and permeabilization, the cells were incubated with phosphor-protein antibody overnight at $4{ }^{\circ} \mathrm{C}$, and then an Alexa Fluor ${ }^{\circledR} 555$-conjugated secondary antibody was used to probe the primary antibody. The cells were washed with PBS and stained with Hoechst 33342 for 5 min $^{[25,26]}$.

To detect the formation of reactive oxygen species (ROS), DL0805-2 (1, 3, and $10 \mu \mathrm{mol} / \mathrm{L})$ was added to VSMCs. After incubation for $2 \mathrm{~h}$, the cells were stimulated by $10^{-6} \mathrm{~mol} / \mathrm{L}$ Ang II for $1 \mathrm{~h}$. ROS in VSMCs was probed with DCFH-DA for $20 \mathrm{~min}$ in an incubator at $37^{\circ} \mathrm{C}$, and cell nuclei were stained with Hoechst 33342 for $5 \min ^{[27,28]}$.

The above fluorescent images and data analyses were obtained using a high-content cytometer (Cellomics ArrayScan VTI HCS reader, Thermo, Waltham, MA, USA).

\section{Intracellular $\left[\mathrm{Ca}^{2+}\right]$ measurements}

Measurement of intracellular free calcium concentration with Fluo-3 acetoxymethyl ester (Fluo-3 AM) was performed as previously described ${ }^{[29,30]}$. The cells were washed three times with HBSS ( $\mathrm{pH}=7.4$ ) of the following composition in $\mathrm{g} / \mathrm{L}$ : $\mathrm{NaCl} 8, \mathrm{Na}_{2} \mathrm{HPO}_{4} \cdot 12 \mathrm{H}_{2} \mathrm{O} 0.126, \mathrm{KCl} 0.4, \mathrm{KH}_{2} \mathrm{PO}_{4} 0.06, \mathrm{MgSO}_{4}$ $0.098, \mathrm{CaCl}_{2}$ 0.14, glucose 1 and $\mathrm{NaHCO}_{3} 0.35$ containing $0.05 \%$ Pluronic F-127. Then, the cells were loaded with $4.4 \mu \mathrm{mol} / \mathrm{L}$ Fluo-3 AM in HBSS for $40 \mathrm{~min}$ at $37^{\circ} \mathrm{C}$. After washing away the excess dye, the cells were pre-incubated with DL0805-2 (1, 3 , and $10 \mu \mathrm{mol} / \mathrm{L}$ ) for $30 \mathrm{~min}$. An automatic microplate reader (EnVision 2104 Multilabel Reader, PerkinElmer Inc, Waltham, MA, USA) was used to add stimulators to the cells and to read the fluorescence values before and after the stimulation. The excitation wavelength was $480 \mathrm{~nm}$, and the emission wavelength was $535 \mathrm{~nm}$.

\section{Statistical analysis}

The results are expressed as the mean \pm SEM. The significance of the differences between groups was determined by one-way or two-way ANOVA as appropriate. The mean values were compared by the Dunnett's post hoc test for multigroup comparisons. Values of $P<0.05$ were considered statistically significant. The images in this article were created using GraphPad Prism 5 (GraphPad Software Inc, La Jolla, CA, USA).

\section{Results}

Inhibitory effect of DL0805-2 on ROCK1

The inhibitory effect of DL0805-2 on ROCK1 was observed by ELISA. As ROCK1 and ROCK2 have up to $92 \%$ homology in their catalytic domains, only ROCK1 was used in our research to reflect the activity of DL0805- ${ }^{[31]}$. When the activity of ROCK1 was inhibited by DL0805-2, the phosphorylation level of Rho kinase substrate would decrease. In addition, the color of the final reaction reflected the potency of DL0805-2. The maximum inhibitory effect $\left(E_{\max }\right)$ of DL0805-2 on ROCK1 is $75.81 \%$, and the $\mathrm{IC}_{50}$ is approximately $1.65 \times 10^{-7} \mathrm{~mol} / \mathrm{L}$ (Figure 2).

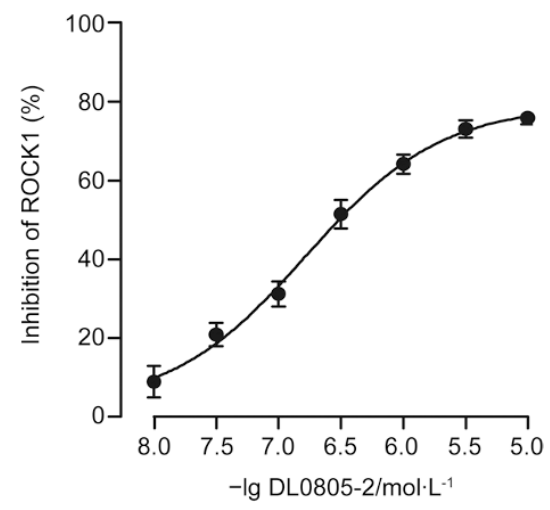

Figure 2. Inhibitory effect of DL0805-2 on ROCK1 activity detected by ELISA. Values are expressed as the mean \pm SEM. $n=5$.

\section{DL0805-2 inhibited the contraction induced by Ang II}

Endothelium-intact or -denuded thoracic aortic rings were preincubated with DL0805-2 at several concentrations $(0.1,0.3,1$, $3,10,30$, and $100 \mu \mathrm{mol} / \mathrm{L}$ ) for $30 \mathrm{~min}$. Only one single dose of Ang II $(0.1 \mu \mathrm{mol} / \mathrm{L})$ was added to the organ bath to stimulate the rings and record the maximum tension. DL0805-2 exerted a concentration-dependent inhibitory effect on the contraction induced by a single dose of Ang II $(0.1 \mu \mathrm{mol} / \mathrm{L})$. According to the results (Figure $3 \mathrm{~A}-\mathrm{B}$ ), the endothelium did not exhibit a significant influence on the vasodilatory effect of DL0805-2. DL0805-2 directly acted on vascular smooth muscle with high potency. Therefore, in the following experiments, only endothelium-denuded aortic rings were used to observe the direct action of DL0805-2 on vascular smooth muscle.

Endothelium-denuded thoracic rings were pre-incubated with DL0805-2 (1, 3, and $10 \mu \mathrm{mol} / \mathrm{L})$ for $30 \mathrm{~min}$ before Ang II $\left(10^{-10}-10^{-7} \mathrm{~mol} / \mathrm{L}\right)$ was cumulatively added to the bath. DL0805-2 (1, 3, and $10 \mu \mathrm{mol} / \mathrm{L})$ inhibited cumulative Ang II-induced contractions of rat thoracic aortic rings in a concentration-dependent manner and produced a rightward shift in the concentration-response curve to Ang II with a significant reduction in the maximal contractile response from $91.20 \% \pm 2.68 \%$ to $72.89 \% \pm 4.11 \%, 53.68 \% \pm 6.00 \%$ and $20.76 \% \pm 3.44 \%$, respectively (Figure 3 C). 

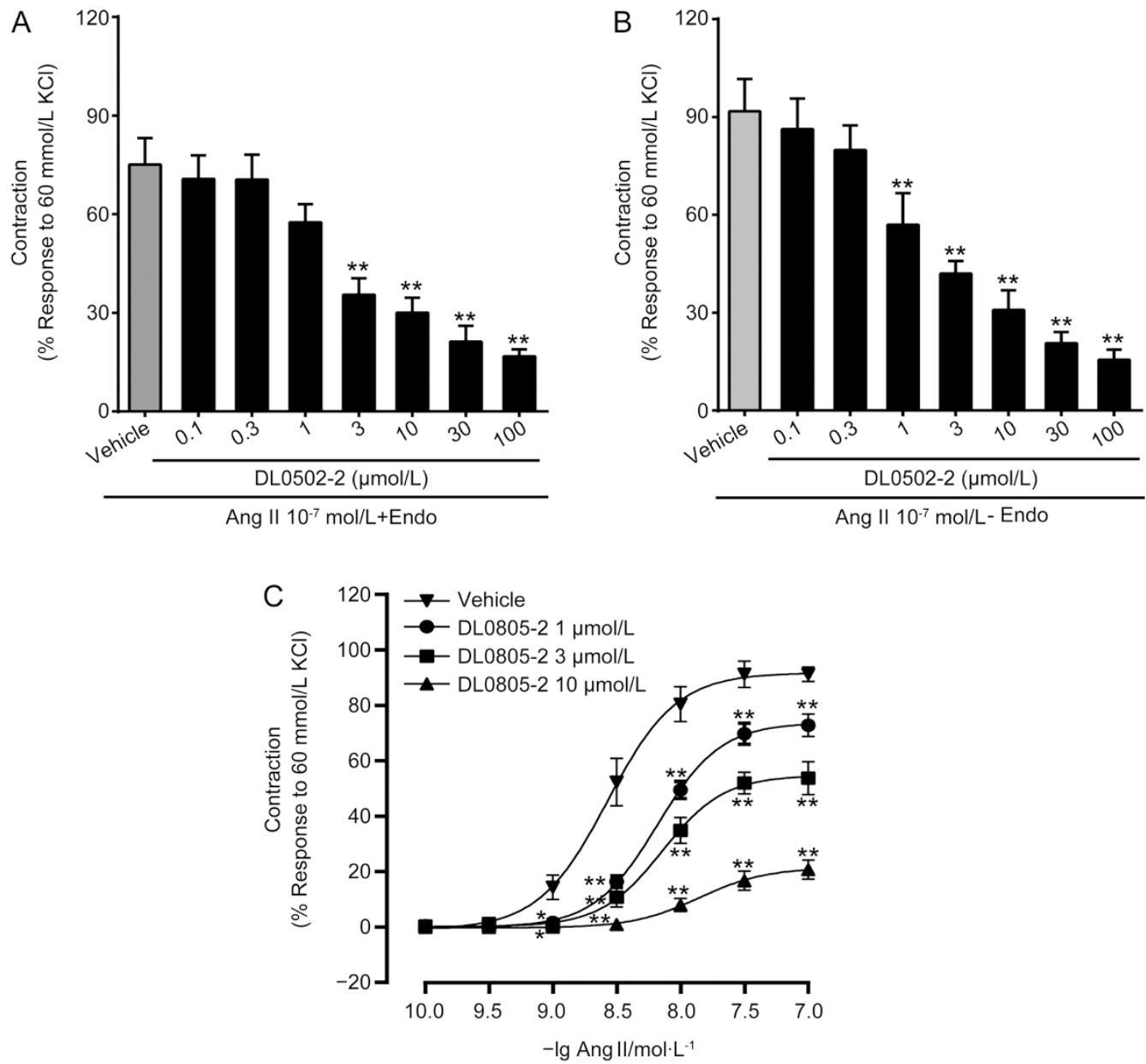

Figure 3. DL0805-2 inhibited the vasoconstriction induced by a single dose of $0.1 \mu \mathrm{mol} / \mathrm{L}$ Ang $\mathrm{II}$ in endothelium-intact (A) and endothelium-denuded (B) isolated aortic rings or by the cumulative addition of Ang II $\left(1 \times 10^{-10}-1 \times 10^{-7} \mathrm{~mol} / \mathrm{L}\right)(\mathrm{C})$. Values are expressed as the mean $\pm \mathrm{SEM}$. $n=7-8$. ${ }^{*} P<0.05$, ${ }^{* *} P<0.01$ vs vehicle.

\section{DL0805-2 may not be an $\mathrm{AT}_{1} \mathrm{R}$ antagonist}

DL0805-2 also exhibited a non-competitive inhibitory effect on KCl- and NE-induced contraction curves (Figure 4A, 4B), indicating that DL0805-2 could not relax the vessels only by antagonizing the Ang II receptors. The results obtained from the molecular docking experiment (Figure 4C, 4D) showed that DL0805-2 barely interacted with $\mathrm{AT}_{1} \mathrm{R}$, while, in the docking model of Rho kinase, DL0805-2 showed significant binding activity very similar to that of the positive control, fasudil, in the same binding pocket of Y27632.

\section{DL0805-2 inhibited Ang II induced $\mathrm{Ca}^{2+}$ fluxes in large aortic} rings

Ang II interacts with the AT1 receptor and stimulates receptoroperated $\mathrm{Ca}^{2+}$ channels to further release intracellular $\mathrm{Ca}^{2+}$. It can also activate voltage-operated $\mathrm{Ca}^{2+}$ channels and induce extracellular $\mathrm{Ca}^{2+}$ influx ${ }^{[32,33]}$. To determine whether DL0805-2 inhibited the transient flux of $\mathrm{Ca}^{2+}$ induced by Ang II, endothelium-denuded thoracic aortic rings in $\mathrm{Ca}^{2+}$-free $\mathrm{K}-\mathrm{H}$ solution were used in the experiment.
DL0805-2 (1, 3, and $10 \mu \mathrm{mol} / \mathrm{L})$ significantly inhibited intracellular $\mathrm{Ca}^{2+}$ release in $\mathrm{Ca}^{2+}$-free $\mathrm{K}-\mathrm{H}$ solution. The inhibition in the vehicle group was considered $100 \%$. The maximal contraction of rings treated by DL0805-2 decreased to $74.85 \% \pm 7.68 \%, 67.53 \% \pm 4.60 \%$, and $42.82 \% \pm 4.23 \%$, respectively (Figure 5A).

As Ang II has a very short duration of action, only a single dose of $\mathrm{Ca}^{2+}(2.5 \mathrm{mmol} / \mathrm{L})$ was used in the extra- $\mathrm{Ca}^{2+}$ influx experiment. DL0805-2 (1, 3, and $10 \mu \mathrm{mol} / \mathrm{L})$ also inhibited the $\mathrm{Ca}^{2+}$ influx induced by Ang II $(1 \mu \mathrm{mol} / \mathrm{L})$ in $\mathrm{Ca}^{2+}$-free $\mathrm{K}-\mathrm{H}$ solution upon the addition of $2.5 \mathrm{mmol} / \mathrm{L} \mathrm{CaCl} \mathrm{Cl}_{2}$ in one portion. The vehicle group was considered $100 \%$. The maximal contraction of DL0805-2 treated rings decreased to $68.22 \% \pm 5.97 \%, 57.24 \% \pm 8.23 \%$, and $30.14 \% \pm 8.82 \%$, respectively (Figure 5B).

DL0805-2 inhibited the phosphorylation levels of MYPT1 and MLC in isolated aortic rings

As a Rho kinase inhibitor, DL0805-2 may also affect the Rho/ ROCK pathway in isolated aortic rings, especially the phos- 

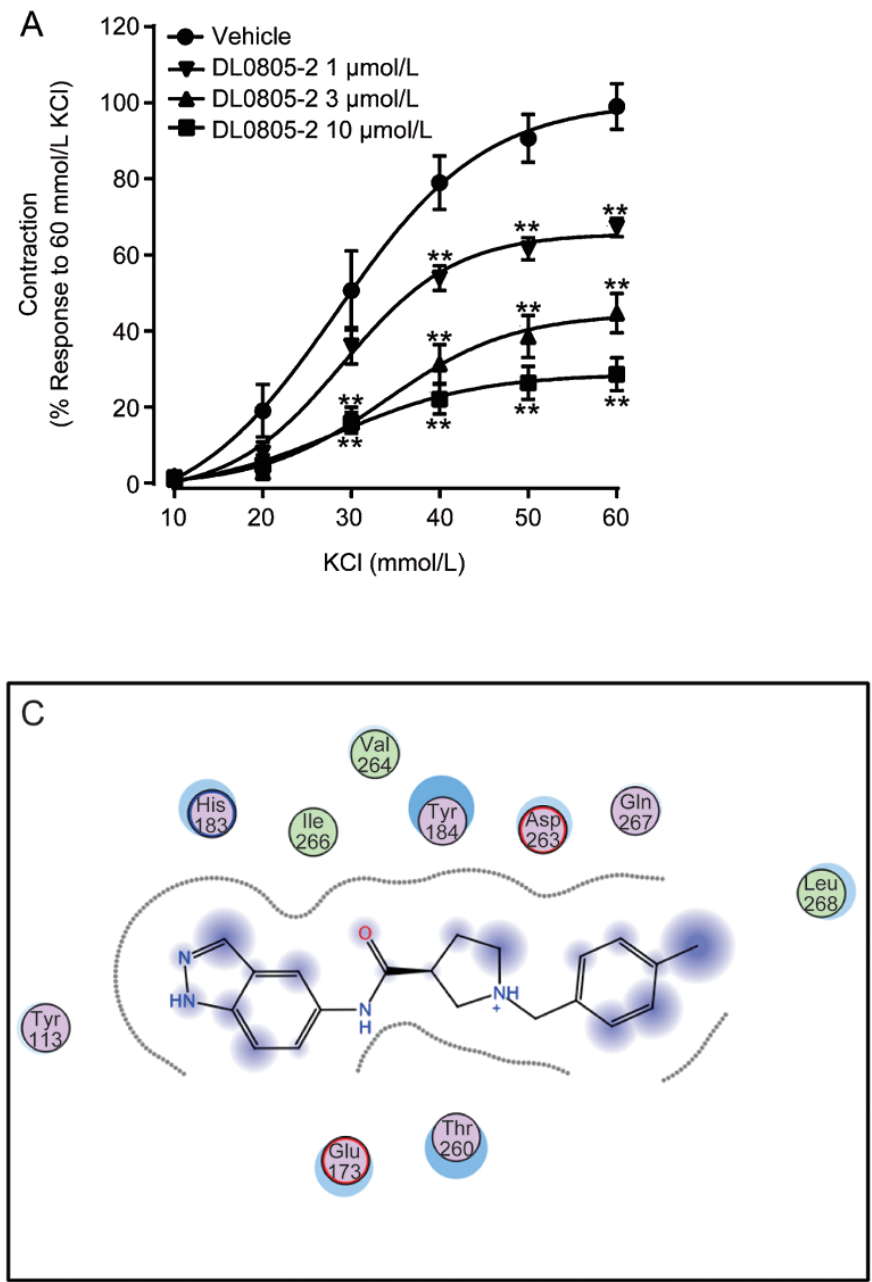
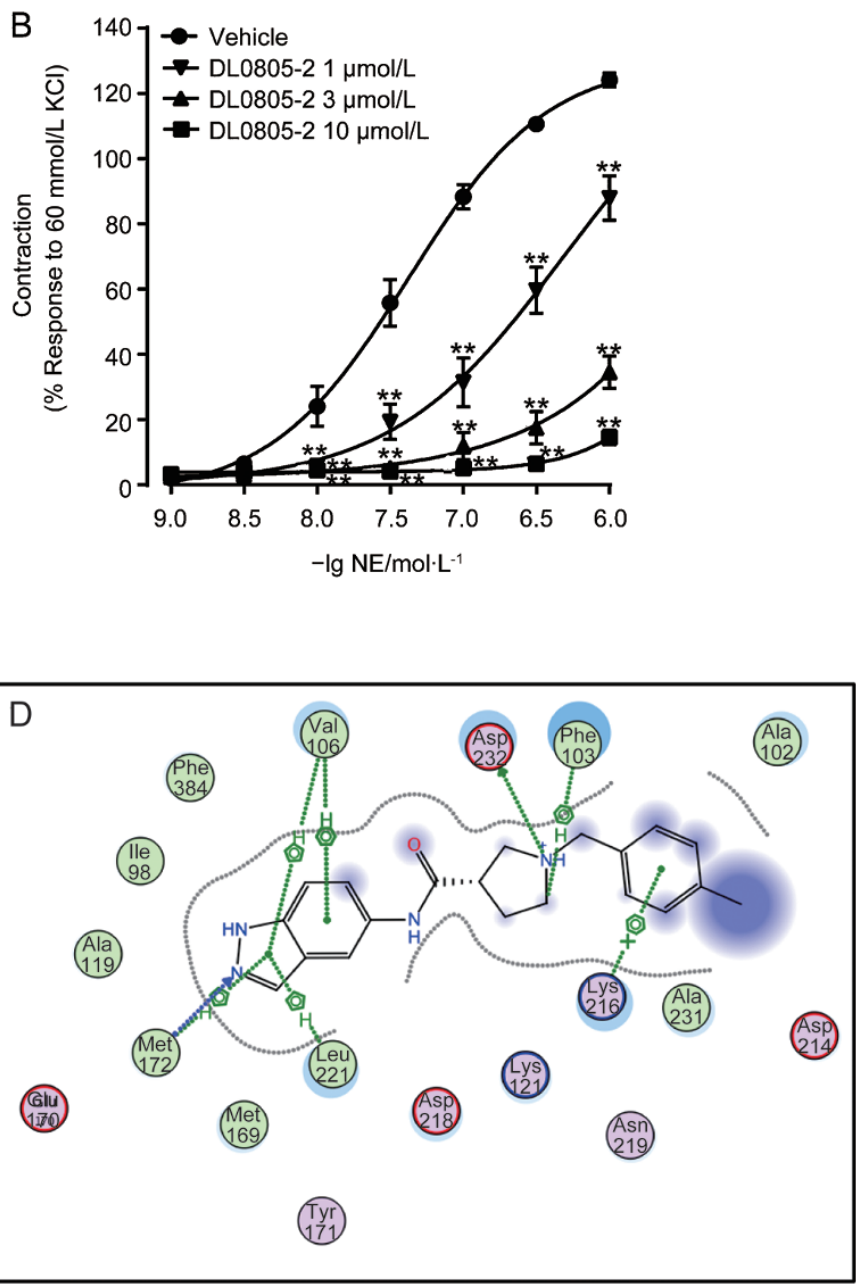

Figure 4. DL0805-2 inhibited the vasoconstriction induced by cumulative addition of $\mathrm{KCl}(10-60 \mathrm{mmol} / \mathrm{L})(\mathrm{A})$ or $\mathrm{NE}\left(10^{-9}-10^{-6} \mathrm{~mol} / \mathrm{L}\right)$. It produced a rightward shift in the concentration-response curve to $\mathrm{KCl}$ or $\mathrm{NE}$ with a significant reduction in the maximal contractile response. The binding modes of compounds interacting with $\mathrm{AT}_{1} \mathrm{R}(\mathrm{PDB}: 1 \mathrm{ZVO})(\mathrm{C})$ and Rho kinase (PDB: $\left.2 \mathrm{H} 9 \mathrm{~V}\right)(\mathrm{D})$. Values are expressed as the mean $\pm \mathrm{SEM}$. $n=8$. ${ }^{* *} P<0.01$ vs vehicle.

A

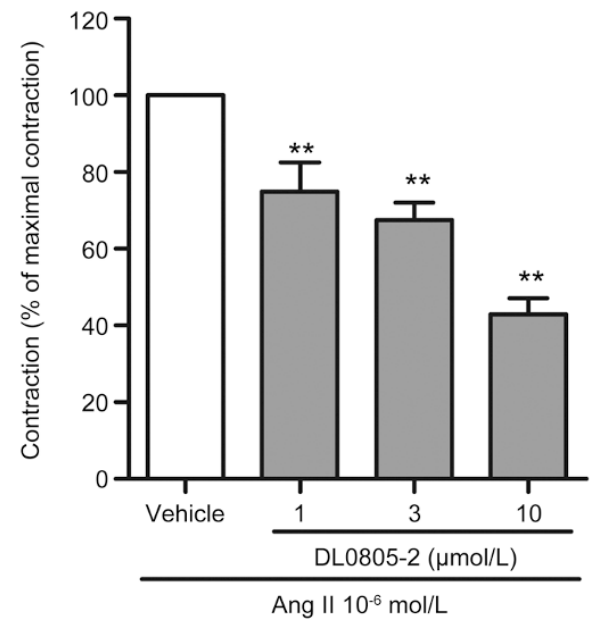

B

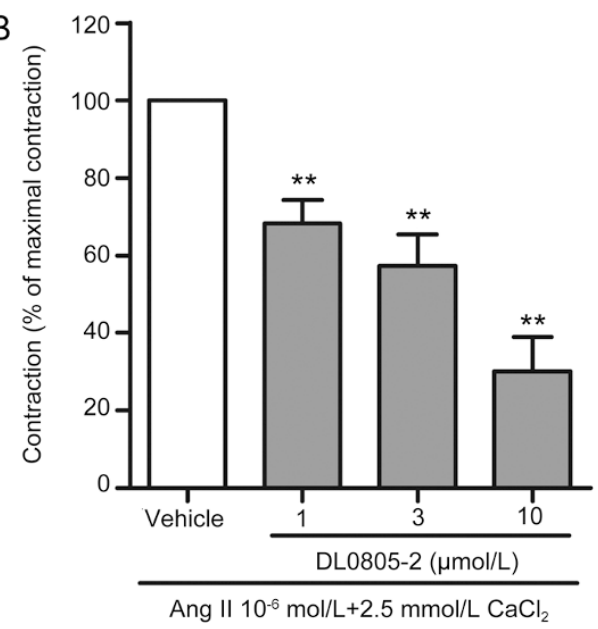

Figure 5. DL0805-2 inhibited intracellular $\mathrm{Ca}^{2+}$ release (A) and extracellular $\mathrm{Ca}^{2+}$ influx (B) induced by $1 \mu \mathrm{mol} / \mathrm{L}$ Ang II in isolated rat aortic rings. Values are expressed as the mean \pm SEM. $n=7$. ${ }^{* *} P<0.01$ vs vehicle. 
phorylation levels of MLC and MYPT1, which are substrates of Rho kinase. The Ang II signaling cascade culminates in the activation of Rho kinase, which results in the phosphorylation of Ser19 on MLC and Thr696 on MYPT1, leading to smooth muscle cell contraction. Western blot analysis was used to examine the phosphorylation of the above-mentioned proteins. The results (Figure 6) showed that pre-incubation with DL0805-2 (1, 3, 10 and $30 \mu \mathrm{mol} / \mathrm{L})$ inhibited the increases in MLC and MYPT1 phosphorylation levels to different degrees induced by Ang II in rat thoracic aortic rings. However, 30 $\mu \mathrm{mol} / \mathrm{L}$ DL0805-2 did not change the basal MLC and MYPT1 phosphorylation levels.

\section{DL0805-2 inhibited ROS production in VSMCs}

Ang II could induce ROS production through activation of NADPH oxidases in VSMCs ${ }^{[34,35]}$. Pre-incubation of VSMCs with DL0805-2 for $2 \mathrm{~h}$ prior to the addition of Ang II (1 $\mu \mathrm{mol} / \mathrm{L})$ decreased the formation of ROS. After $1 \mathrm{~h}$ of stimulation by Ang II, ROS generation in VSMCs increased to $142.8 \% \pm 7.7 \%$ of the control. DL0805-2 $(1,3$, and $10 \mu \mathrm{mol} / \mathrm{L})$ diminished VSMCs ROS generation in the presence of Ang II to only $109.8 \% \pm 3.0 \%, 97.6 \% \pm 9.2 \%$, and $95.0 \% \pm 5.1 \%$ of the control, respectively (Figure 7).

\section{DL0805-2 inhibited F-actin formation in VSMCs}

It is well known that actin stress fiber formation is induced by the activation of Rho kinase in several types of cells and tissues $^{[36]}$. Thus, the cellular effect of DL0805-2 on actin stress fiber formation was tested in VSMCs. The results showed that pre-incubation with DL0805-2 (1, 3, and $10 \mu \mathrm{mol} / \mathrm{L})$ could slightly decrease F-actin formation induced by Ang II, and 10 rmol/L DL0805-2 exhibited a significant inhibitory effect

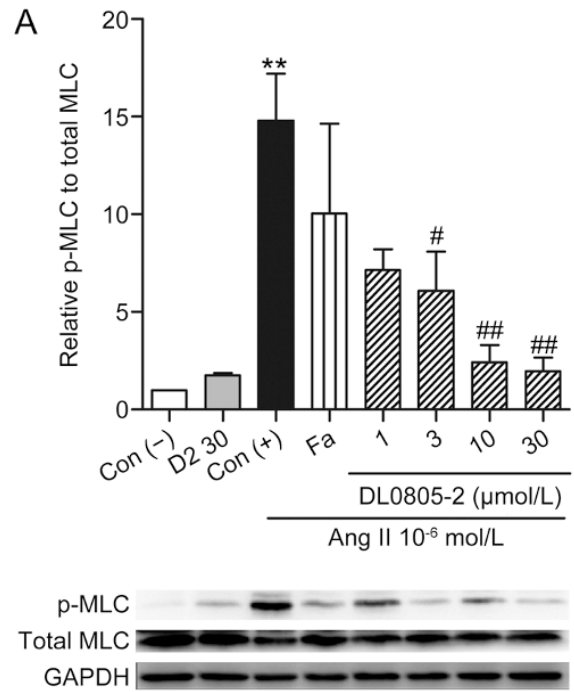

(Figure 8).

DL0805-2 inhibited the phosphorylation levels of the downstream substrates of Rho kinase in VSMCs

The activation of Rho kinase can directly phosphorylate its downstream substrates ERM and Limk, while cofilin, as the substrate of Limk, is an indirect substrate of Rho kinase. Its phosphorylation level will be increased when the activity of Rho kinase is high ${ }^{[3,37]}$. Pre-incubation with DL0805-2 (1, 3, and $10 \mu \mathrm{mol} / \mathrm{L}$ ) will significantly decrease the phosphorylation levels of these three direct or indirect substrates of Rho kinase (Figure 9).

Western blot analysis showed that DL0805-2 also blunted Ang II-induced Rho kinase activation in VSMCs. The phosphorylation levels of MLC and MYPT1 were significantly reduced by pre-incubation with DL0805-2, while $10 \mu \mathrm{mol} / \mathrm{L}$ DL0805-2 had little influence on basic protein phosphorylation levels. The results obtained in VSMCs were similar to those obtained in aortic rings (Figure 10).

\section{DL0805-2 inhibited the Ang II-induced $\left[\mathrm{Ca}^{2+}\right]_{i}$ increase in VSMCs}

To determine whether DL0805-2 could decrease intracellular calcium concentration, VSMCs in normal HBSS were used. When $10^{-6} \mathrm{~mol} / \mathrm{L}$ Ang II was added to the cells, the value of fluorescence indicating the inner calcium concentration quickly increased up to $5.76 \pm 0.89$-fold vs control. Pre-incubation with DL0805-2 $(1,3$, and $10 \mu \mathrm{mol} / \mathrm{L})$ could decrease the change in inner $\mathrm{Ca}^{2+}$ down to $4.02 \pm 1.35-, 3.77 \pm 1.12$ - and $2.23 \pm$ 0.63 -fold vs control (Figure 11A).

Further experiments revealed that DL0805-2 inhibited the change in inner $\mathrm{Ca}^{2+}$ through both intracellular $\mathrm{Ca}^{2+}$ release and extracellular $\mathrm{Ca}^{2+}$ influx, which accounted for the elevation

B
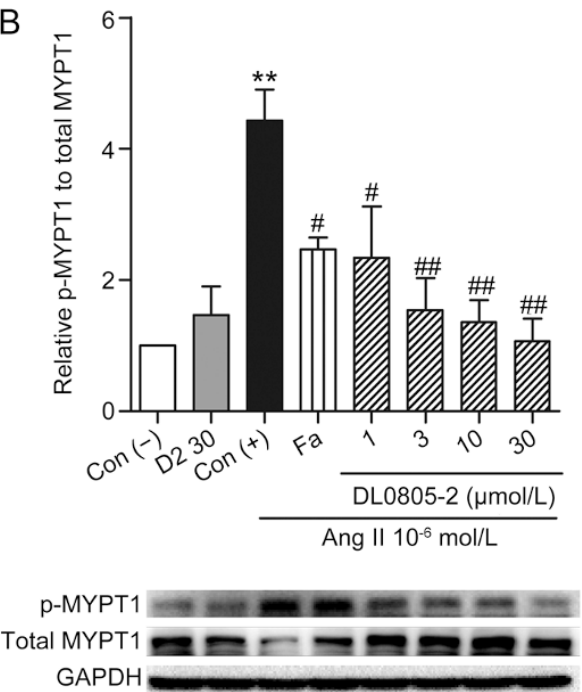

Figure 6. Effect of DL0805-2 on the phosphorylation levels of MLC (A) or MYPT1 (B) in Ang II-treated rat thoracic aortas. Representative Western blots for phosphor-MLC (18 kDa) and total-MLC (18 kDa) or phosphor-MYPT1 (140 kDa) and total-MYPT1 (140 kDa) are shown in the lower panel. Densitometric analysis of the Western blot is shown in the upper panel. Con (-) represents the negative control, which vessels were not treated with both DL0805-2 and Ang II. Con (+) represents the positive control, which were vessels only treated with Ang II. D2 30 represents the vessels that were treated with $30 \mu \mathrm{mol} / \mathrm{L}$ DL0805-2 but not Ang II. Values are expressed as the mean \pm SEM. $n=3 .{ }^{* *} P<0.01$ vs Con (-). ${ }^{\#} P<0.05$, ${ }^{\# \#} P<0.01$ vs Con (+). 
A
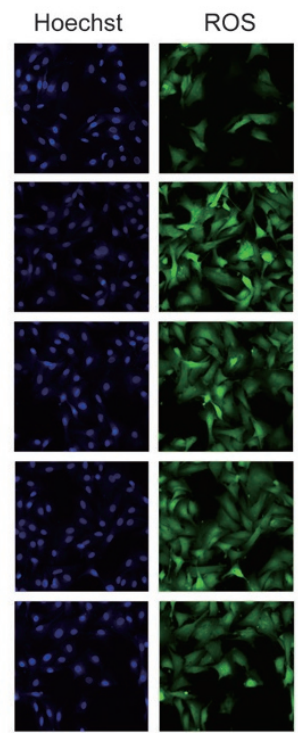

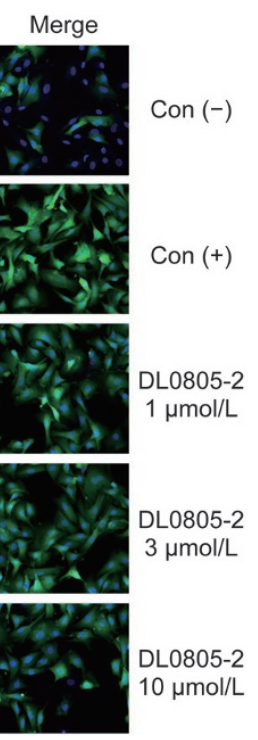

Figure 7. Immunofluorescent staining for ROS formation in VSMCs. DL0805-2 (1, 3, and $10 \mu \mathrm{mol} / \mathrm{L}$ ) inhibited ROS formation in VSMCs induced by Ang II (1 $\mu \mathrm{mol} / \mathrm{L})$. Representative images of ROS production, which were produced by a high-content cytometer, are shown in the left panels (A), while analysis of total ROS production is shown in the right panel (B). Values are expressed as the mean \pm SEM. $n=3 .{ }^{* *} P<0.01$ vs Con $(-)$. ${ }^{\# \#} P<0.01$ vs Con $(+)$.
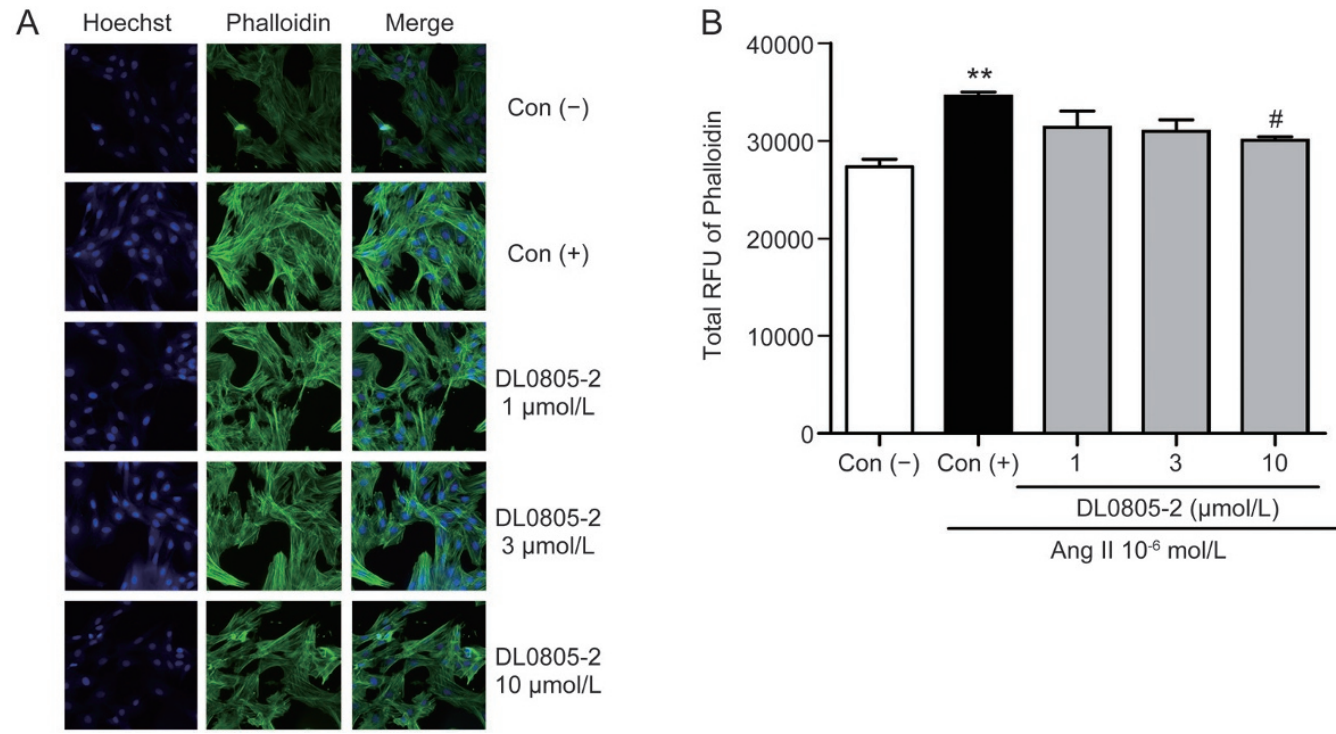

Figure 8. Immunofluorescent staining for actin stress fiber formation in VSMCs. DL0805-2 (1, 3, and $10 \mu$ mol/L) inhibited F-actin formation in VSMCs induced by Ang II $(1 \mu \mathrm{mol} / \mathrm{L})$. Representative images of F-actin production, which were produced by a high-content cytometer, are shown in the left panels (A), while analysis of total F-actin production is shown in the right panel (B), which was read by a PE microplate reader. Values are expressed as the mean \pm SEM. $n=3 .{ }^{* *} P<0.01$ vs Con $(-) .{ }^{*} P<0.05$ vs Con $(+)$.

of $\mathrm{Ca}^{2+}$ in VSMCs. To test the inhibitory effect of DL0805-2 on intracellular $\mathrm{Ca}^{2+}$ release, $\mathrm{Ca}^{2+}$-free HBSS was used to wash away the extracellular $\mathrm{Ca}^{2+}$ of cultured VSMCs. Then, after pre-incubation with DL0805-2, Ang II was added to stimulate the release of $\mathrm{Ca}^{2+}$. DL0805-2 (1, 3, and $\left.10 \mu \mathrm{mol} / \mathrm{L}\right)$ decreased $\mathrm{Ca}^{2+}$ release from $2.91 \pm 0.18$ - to $2.33 \pm 0.43-, 1.94 \pm 0.35$ - and $1.36 \pm 0.11$-fold vs control, respectively (Figure $11 \mathrm{~B})$. To test the inhibitory effect of DL0805-2 on extracellular $\mathrm{Ca}^{2+}$ influx, $\mathrm{Ca}^{2+}$ free HBSS with $1 \mathrm{mmol} / \mathrm{L}$ EGTA was used to wash away all of the $\mathrm{Ca}^{2+}$ of cultured VSMCs. After an approximately $2 \mathrm{~min}$ pre-stimulation with $1 \times 10^{-6} \mathrm{~mol} / \mathrm{L}$ Ang II, a final concentration of $1.8 \mathrm{mmol} / \mathrm{L} \mathrm{CaCl}_{2}$ was added to the cells to induce the extracellular influx. DL0805-2 (1, 3, and $10 \mu \mathrm{mol} / \mathrm{L})$ decreased $\mathrm{Ca}^{2+}$ influx from $3.43 \pm 0.43$ - to $2.22 \pm 0.52-, 1.35 \pm 0.28-$ and $1.32 \pm 0.25$-fold $v$ s control, respectively (Figure 11C). Based on these results, it appears that DL0805-2 exhibits more potent efficacy on extracellular influx than intracellular release. 


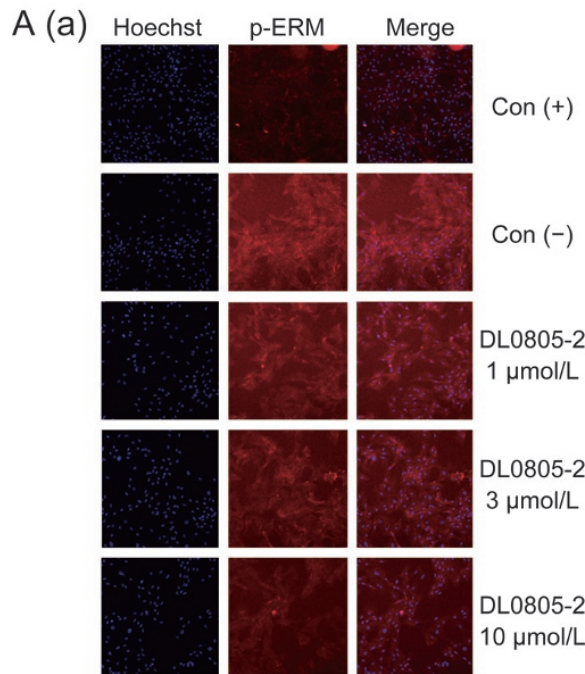

B (a)

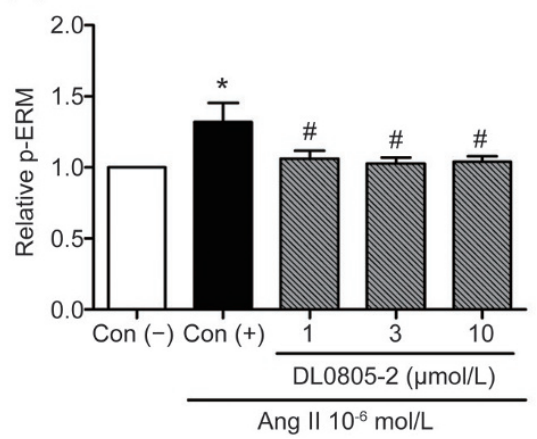

(b)

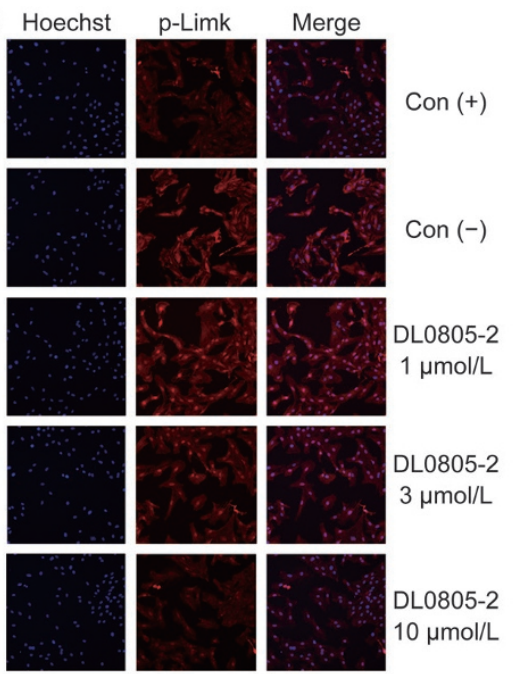

(b)

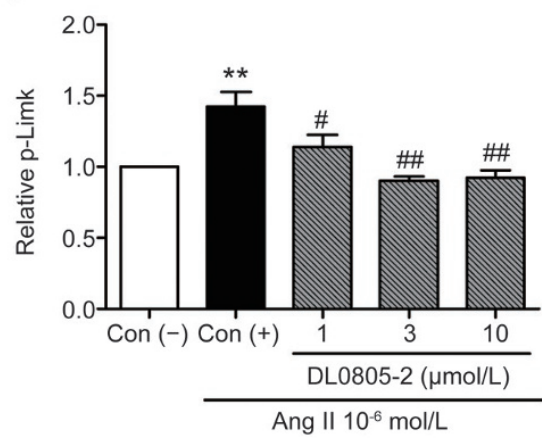

(c)

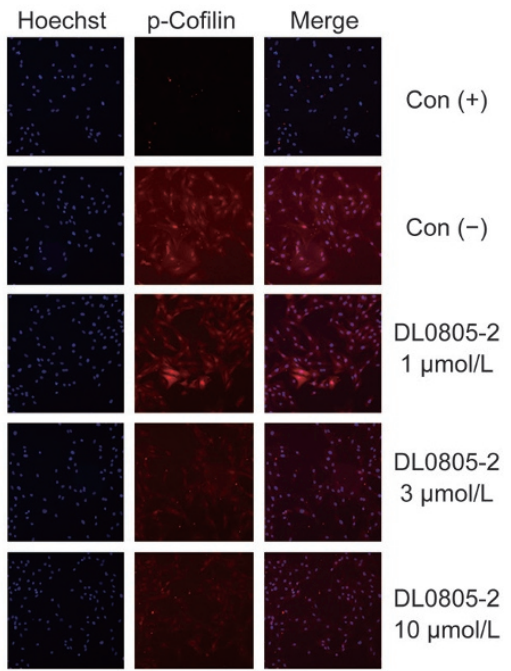

(c)

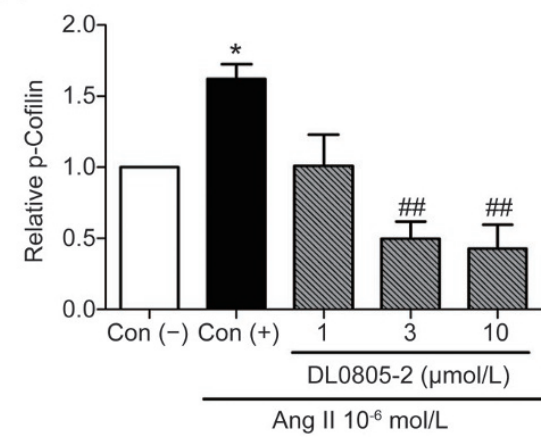

Figure 9. DL0805-2 decreased the phosphorylation levels induced by $10^{-6} \mathrm{~mol} / \mathrm{L}$ Ang II of three types of Rho kinase substrates: ERM (a), Limk (b) and cofilin (c). Representative images of phosphorylated proteins, which were produced by a high-content cytometer, are shown in the upper panels (A), while the relative phosphorylation levels, which were calculated by the Cellomics scan software in a high-content cytometer, are shown in the lower panel (B). Values are expressed as the mean \pm SEM. $n=3 .{ }^{*} P<0.05,{ }^{* *} P<0.01$ vs Con (-). ${ }^{\#} P<0.05,{ }^{\# \#} P<0.01$ vs Con (+).

\section{Discussion}

Several indazole compounds have been found to be active in Rho kinase inhibition ${ }^{[36,38]}$. Additionally, in our previous work, a new chemical entity, 5-nitro-1(2)H-indazole3-carbonitrile (DL0805), was discovered as a new Rho kinase inhibitor with an $\mathrm{IC}_{50}$ of $6.67 \mu \mathrm{mol} / \mathrm{L}$. DL0805 was derived from the compound library in our laboratory through HTS as previously described ${ }^{[14]}$. Although DL0805 exerted a significant vasorelaxant effect in a dose-dependent manner ${ }^{[13]}$, it was found to be toxic both in vivo and in vitro. In a mouse acute toxicity trial, the $\mathrm{LD}_{50}$ of intravenous administration of DL0805 was $33.01 \mathrm{mg} / \mathrm{kg}$. Therefore, we optimized the structure of DL0805 and obtained more than 100 new indazole compounds. Among these compounds, DL0805-2, which has a totally new structure, shows superiority in Rho kinase inhibition, vasorelaxation and toxicity. The $\mathrm{IC}_{50}$ of DL0805-2 on ROCKI is approximately $0.165 \mu \mathrm{mol} / \mathrm{L}$, which is close to that of Fasudil (HA-1077) and Y27632 and is more potent than DL0805 ${ }^{[39]}$. On NE pre-contracted isolated thoracic aortic rings, the $\mathrm{pEC}_{50}$ of DL0805-2 is approximately 5.68, while that of DL0805 is 4.54. DL0805-2 has a much stronger effect on vasodilation than DL0805. DL0805-2 also exhibits a relaxant effect on vessels contracted by various constrictors, including $\mathrm{KCl}, 5-\mathrm{HT}, \mathrm{U} 46619, \mathrm{ET}-1, \mathrm{NaF}, \mathrm{PDBu}$ and vasopressin. DL0805-2 has lower in vivo toxicity. The $\mathrm{LD}_{50}$ of intravenous administration of DL0805-2 was $70.90 \mathrm{mg} / \mathrm{kg}$. In summary, DL0805-2 exhibits better efficacy in Rho kinase inhibition and vasodilation than DL0805 but has lower toxicity. The superiority of DL0805-2 makes it more valuable than DL0805 for further studies. In the present study, the possible use of DL0805 for the treatment of hypertension was analyzed.

Ang II, a vital bioactive peptide of the renin-angiotensin system (RAS), plays an important physiological role in maintaining vascular tone by regulating immediate vasoconstriction in the cardiovascular system ${ }^{[40]}$. Among various humoral factors involved in vascular alterations in hypertension, Ang II appears to be one of the most important factors. It induces vasoconstriction via the activation of the angiotensin type 1 receptor $\left(\mathrm{AT}_{1} \mathrm{R}\right)$ in smooth muscle cells, which results from the activation of phospholipase $\mathrm{C}$ and the increase of cytoplasmic 

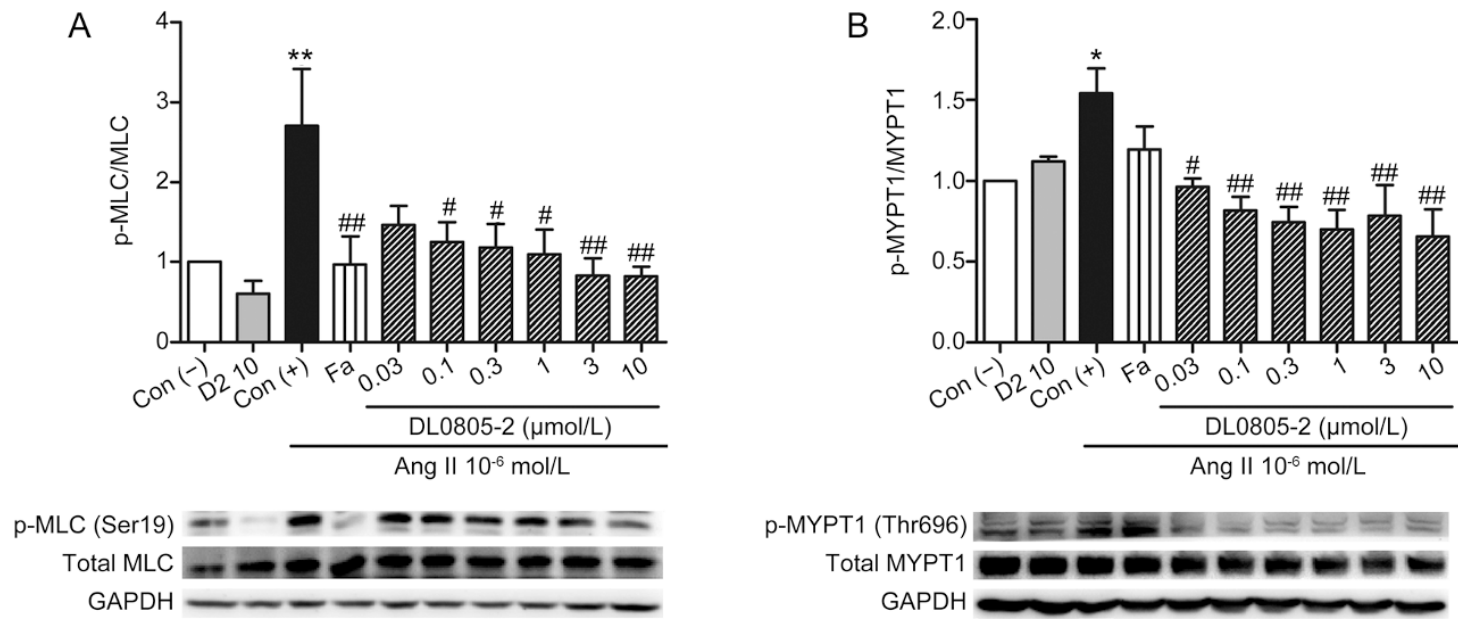

Figure 10. Effect of DL0805-2 on the phosphorylation levels of MLC (A) or MYPT1 (B) in Ang II-treated VSMCs. Representative Western blots for phosphor-MLC (18 kDa) and total-MLC (18 kDa) or phospho-MYPT1 (140 kDa) and total-MYPT1 (140 kDa) are shown in the lower panel. Densitometric analysis of the Western blot is shown in the upper panel. D2 10 represents the cells that were treated with $10 \mu \mathrm{mol} / \mathrm{L}$ DL0805-2 but not Ang II. Values are expressed as the mean \pm SEM. $n=4 .{ }^{*} P<0.05,{ }^{* *} P<0.01$ vs Con $(-) .{ }^{\#} P<0.05,{ }^{\# \#} P<0.01$ vs Con $(+)$.
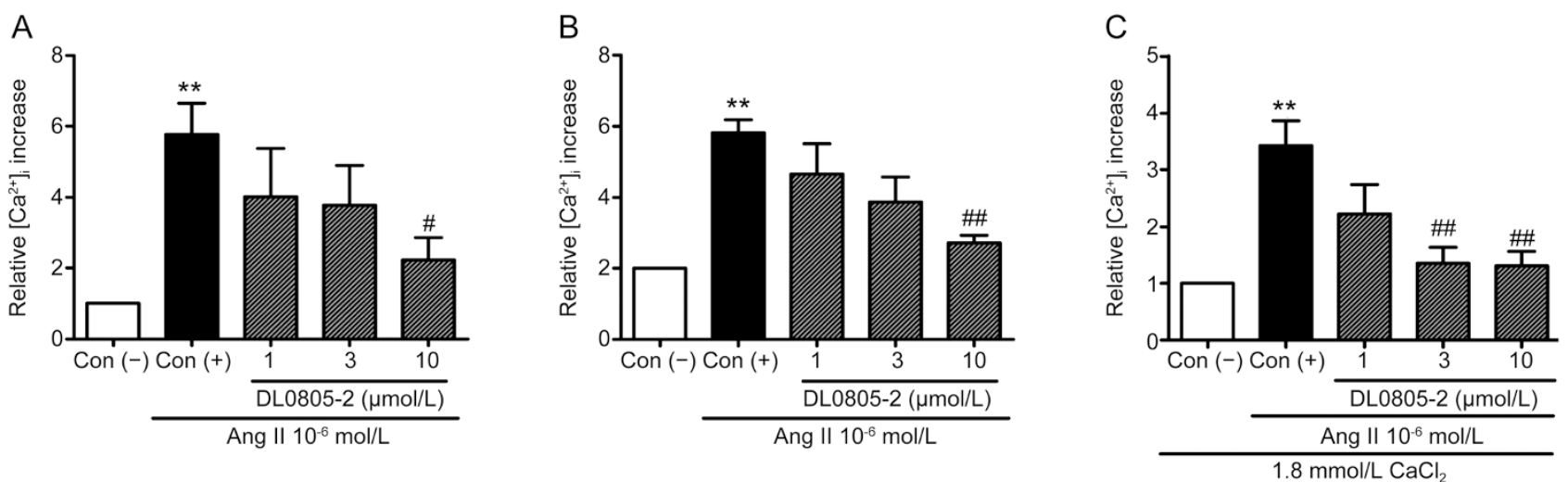

Figure 11. Effects of DL0805-2 (1, 3, and $10 \mu \mathrm{mol} / \mathrm{L})$ on the $\mathrm{Ca}^{2+}$ flux stimulated by Ang II in VSMCs. After being loaded with Fluo 3-AM, the cells were washed with normal HBSS (A), $\mathrm{Ca}^{2+}$-free HBSS (B) or $\mathrm{Ca}^{2+}$-free HBSS with $1 \mathrm{mmol} / \mathrm{L}$ EGTA (C). Pre-incubation with DL0805-2 inhibited Ang Il-induced intracellular $\mathrm{Ca}^{2+}$ concentration changes in normal HBSS (A). It also inhibited intracellular $\mathrm{Ca}^{2+}$ release in $\mathrm{Ca}^{2+}$-free $\mathrm{HBSS}$ (B) and extracellular influx in $\mathrm{Ca}^{2+}$-free HBSS when $1.8 \mathrm{mmol} / \mathrm{L} \mathrm{CaCl}_{2}$ was added (C). Values are expressed as the mean \pm SEM. $n=6$. ${ }^{* *} P<0.01$ vs Con (-). ${ }^{\#} P<0.05$, ${ }^{\# \#} P<0.01$ vs Con $(+)$.

calcium concentrations ${ }^{[41,42]}$. In addition, when binding to the $\mathrm{AT}_{1} \mathrm{R}$, Ang II regulates the low weight guanosine triphosphatase RhoA and indirectly activates Rho kinase by increasing the amount of GTP-bound RhoA ${ }^{[43]}$, which promotes contraction of cells via the phosphorylation of downstream proteins $^{[44,45]}$. Therefore, in our study, Ang II was used as the stimulator to contract the aortic rings and smooth muscle cells, and the protective effects and underlying mechanisms of the Rho kinase inhibitor DL0805-2 on such organs and cells were detected.

The present study revealed that DL0805-2 exerted a concentration-dependent vasorelaxant effect on Ang II-induced aortic ring constriction. Pre-incubation with DL0805-2 could attenuate the contraction induced by a single dose of Ang II $\left(1 \times 10^{-7}\right.$ $\mathrm{mol} / \mathrm{L}$ ) and produced a rightward shift in the concentration- response curve of Ang II $\left(1 \times 10^{-10}-1 \times 10^{-7} \mathrm{~mol} / \mathrm{L}\right)$ with a significant reduction in the maximal contractile response. This study revealed that DL0805-2 exhibits a strong vasorelaxant effect on isolated large aortic rings and non-competitive antagonism of Ang II-induced contractions. In addition, DL0805-2 not only had a potent inhibitory effect on the contraction induced by Ang II but also inhibited the contraction induced by other vasoconstrictors. In another experiment, DL0805-2 showed non-competitive antagonism to $\mathrm{KCl}$ and NE-induced contraction curves. It also produced a right shift in the contraction curves and reduced the maximum contraction response. If DL0805-2 relaxes the vessels only through the blockage of $\mathrm{AT}_{1} \mathrm{R}$, it should not have an effect on vessels contracted by other vasoconstrictors ${ }^{[46,47]}$. Moreover, a preliminary study carried out using a computational molecular docking method 
showed that DL0805-2 did not have a significant interaction with $\mathrm{AT}_{1} \mathrm{R}$ as was observed for the positive control losartan. Therefore, DL0805-2 is not regarded as an $\mathrm{AT}_{1} \mathrm{R}$ antagonist, and its underlying mechanisms need to be further investigated.

Ang II interacts with $\mathrm{AT}_{1} \mathrm{R}$ and typically mediates a biphasic $\left[\mathrm{Ca}^{2+}\right]_{i}$ response to induce the contraction of aortic rings, which consists of a rapid initial transient phase followed by a sustained plateau ${ }^{[48]}$. The initial transient phase is primarily characterized by $\mathrm{IP}_{3}$-induced intracellular $\mathrm{Ca}^{2+}$ mobilization from the sarcoplasmic reticulum, which is also referred to as intracellular $\mathrm{Ca}^{2+}$ release. The sustained phase is dependent on an influx of $\mathrm{Ca}^{2+}$ from the extracellular medium ${ }^{[49-51]}$. In our experiment, pre-incubation with DL0805-2 suppressed the Ang II-induced intracellular $\mathrm{Ca}^{2+}$ release and extracellular $\mathrm{Ca}^{2+}$ influx on both isolated aortic rings and VSMCs. $\mathrm{Ca}^{2+}$ fluxes in isolated vessels were represented by the contraction of aortic rings. DL0805-2 effectively inhibited such $\mathrm{Ca}^{2+}$ flux-induced vasoconstriction. DL0805-2 can also inhibit the extracellular calcium influx induced by $60 \mathrm{mmol} / \mathrm{L} \mathrm{KCl}$ or $1 \mu \mathrm{mol} / \mathrm{L} \mathrm{NE}$ and the intracellular calcium release induced by $1 \mu \mathrm{mol} / \mathrm{L} \mathrm{NE}$ (unpublished data). In other words, the inhibition of Ang IIinduced vasoconstriction in $\mathrm{Ca}^{2+}$-free medium by DL0805-2 and the inhibition of the contraction induced by the addition of $\mathrm{CaCl}_{2}$ to the preparation are not due to the blockage of $\mathrm{AT}_{1} \mathrm{R}$.

The Ang II-induced vascular contraction involves the activation of the Rho/ROCK pathway as mentioned above. As a Rho kinase inhibitor, DL0805-2 significantly suppressed the phosphorylation levels of MYPT1 and MLC, which are direct substrates of Rho kinase.

In the primary cultured rat thoracic aortic smooth muscle cells, we have obtained similar results to those obtained with the isolated aortic rings. Ang II had significant pro-inflammatory actions on the vascular wall and induced ROS production through the activation of NADPH oxidases in VSMCs ${ }^{[34,35]}$. ROS mediates vascular hypertrophy and precipitates the dysfunction of VSMCs. It is an important stimulator in the development of hypertension ${ }^{[52]}$. Ang II also induces actin stress fiber formation in VSMCs and plays a vital role in vascular remodeling ${ }^{[53,54]}$. Both of the above phenomena are related to the activation of Rho kinase ${ }^{[42,55]}$. Pre-incubation with DL0805-2 decreased the formation of ROS and stress fibers in VSMCs through the inhibition of Rho kinase. DL0805-2 suppressed the intracellular $\mathrm{Ca}^{2+}$ concentration in VSMCs that was induced by Ang II. The decrease in intracellular $\mathrm{Ca}^{2+}$ will lower the tension of cells and further relax vessels. The inhibition of calcium concentration in VSMCs, which is directly reflected by fluorescence probes, shows that DL0805-2 indeed has an impact on $\mathrm{Ca}^{2+}$ fluxes. Furthermore, DL0805-2 down-regulated the phosphorylation levels of the direct Rho kinase substrates ERM, Limk, MYPT1 and MLC, as well as the indirect Rho kinase substrate cofilin. Interestingly, the basal MLC and MYPT1 phosphorylation levels in both aortic rings and VSMCs are not significantly reduced by DL0805-2. This phenomenon is in accordance with the non-inhibitory effect of
DL0805-2 on the basal tension of isolated aortic rings.

In a preliminary computational molecular docking experiment, DL0805-2 was found to more potently interact with Rho kinase, instead of $\mathrm{AT}_{1} \mathrm{R}$. It is believed that DL0805-2 inhibits the activity of Rho kinase to down-regulate the phosphorylation levels of several Rho kinase substrates and to further relax the vascular smooth muscle. It also decreases the calcium sensitivity of smooth muscle cells via the inhibition of Rho kinase. DL0805-2 also blocks the calcium flux including the extracellular calcium influx and intracellular calcium release. However, more experiments are required to clarify the exact interaction between DL0805-2 and calcium channels.

At present, in the pre-trial in vivo, DL0805-2 was found to be effective on hypertension crisis. It can steadily lower the blood pressure to a value within the safety range in a short time, and it does not cause hypotension. It also exhibited a protective effect on organs injured by high blood pressure, especially on the lungs and brain. As a Rho kinase inhibitor and calcium flux blocker, DL0805-2 might show some advantages in the treatment of hypertension crisis. Efforts have been made to develop DL0805-2 as an emergency anti-hypertension agent.

\section{Conclusions}

Taken together, the results suggest that DL0805-2 prevents Ang II-induced vascular contraction in vitro by inhibiting both Ang II-induced elevation in intracellular $\mathrm{Ca}^{2+}$ and Rho/ROCK pathway activation. This work may contribute to the understanding of the molecular mechanisms of DL0805-2 in the vascular system and to the further development of DL0805-2 as an anti-hypertension drug. In addition, it may provide references for the investigation of novel indazole compounds targeting cardiovascular system diseases.

\section{Acknowledgements}

This study was supported by the National Natural Science Foundation of China (No 81573645), the National Scientific \& Technological Major Special Project "significant creation of new drugs" (№ 2013ZX09103001-008, 2012ZX09103101-078, 2013ZX09508104) and the Central Public Scientific Research Institution Fundamental Project (№ 2016CX09). We are grateful to Dr Jian-song FANG for help with the molecular docking experiment.

\section{Author contribution}

Tian-yi YUAN designed the experiments, drafted the manuscript and participated in the Western blotting assay; Yu-cai CHEN, Hui-fang ZHANG and Li LI prepared the reagents and thoracic aortas and measured isometric vascular tension; Xiaozhen JIAO and Ping XIE prepared the DL0805-2 sample; and Lian-hua FANG and Guan-hua DU carried out the statistical analysis, participated in the experimental design and drafted the manuscript.

\section{References}

1 Flack JM, Peters R, Shafi T, Alrefai H, Nasser SA, Crook E. Prevention of hypertension and its complications: theoretical basis and guidelines 
for treatment. J Am Soc Nephrol 2003; 14 (7 Suppl 2): S92-98.

2 Budzyn K, Marley PD, Sobey CG. Targeting Rho and Rho-kinase in the treatment of cardiovascular disease. Trends Pharmacol Sci 2006; 27: 97-104.

3 Zhou Q, Gensch C, Liao JK. Rho-associated coiled-coil-forming kinases (ROCKs): potential targets for the treatment of atherosclerosis and vascular disease. Trends Pharmacol Sci 2011; 32: 167-73.

4 Zhao Y, Lv M, Lin H, Hong Y, Yang F, Sun Y, et al. ROCK1 induces ERK nuclear translocation in PDGF-BB-stimulated migration of rat vascular smooth muscle cells. IUBMB Life 2012; 64: 194-202.

5 Schmandke A, Schmandke A, Strittmatter SM. ROCK and Rho: biochemistry and neuronal functions of Rho-associated protein kinases. Neuroscientist 2007; 13: 454-69.

6 Shi JJ, Wei L. Rho kinase in the regulation of cell death and survival. Arch Immunol Ther Exp (Warsz) 2007; 55: 61-75.

7 Noma K, Oyama N, Liao JK. Physiological role of RoCKs in the cardiovascular system. Am J Physiol Cell Physiol 2006; 290: C661-8.

8 Wirth A. Rho kinase and hypertension. Biochim Biophys Acta 2010; 1802: $1276-84$.

9 Coca A, Mazón P, Aranda P, Redón J, Divisón JA, Martínez J, et al. Role of dihydropyridinic calcium channel blockers in the management of hypertension. Expert Rev Cardiovasc Ther 2013; 11: 91-105.

10 Shin WS, Oh S, An SW, Park GM, Kwon D, Ham J, et al. 5E- and 5Z-farnesylacetones from Sargassum siliquastrum as novel selective L-type calcium channel blockers. Vascul Pharmacol 2013; 58: 299306.

11 Kang P, Suh SH, Min SS, Seol GH. The essential oil of Citrus bergamia Risso induces vasorelaxation of the mouse aorta by activating $\mathrm{K}^{+}$ channels and inhibiting $\mathrm{Ca}^{2+}$ influx. J Pharm Pharmacol 2013; 65: 745-9.

12 Cekic EG, Soydan G, Guler S, Babaoglu MO, Tuncer M. Propranololinduced relaxation in the rat basilar artery. Vascul Pharmacol 2013; 58: $307-12$

13 Gong LL, Peng JH, Fang LH, Xie P, Si K, Jiao XZ, et al. The vasorelaxant mechanisms of a Rho kinase inhibitor DL0805 in rat thoracic aorta. Molecules 2012; 17: 5935-44.

14 Gong LL, Fang LH, Peng JH, Liu AL, Du GH. Integration of virtual screening with high-throughput screening for the identification of novel Rho-kinase I inhibitors. J Biotechnol 2010; 145: 295-303.

15 Yuan TY, Yan Y, Wu YJ, Xu XN, Li L, Jiao XZ, et al. Vasodilatory effect of a novel Rho-kinase inhibitor, DL0805-2, on the rat mesenteric artery and its potential mechanisms. Cardiovasc Drugs Ther 2014; 28 : 415-24.

16 Lee K, Jung J, Yang G, Ham I, Bu Y, Kim H, et al. Endotheliumindependent vasorelaxation effects of Sigesbeckia glabrescens (Makino) Makino on isolated rat thoracic aorta. Phytother Res 2013; 27: 1308-12.

17 Senejoux F, Demougeot C, Cuciureanu M, Miron A, Cuciureanu R, Berthelot $\mathrm{A}$, et al. Vasorelaxant effects and mechanisms of action of Heracleum sphondylium $L$ (Apiaceae) in rat thoracic aorta. J Ethnopharmacol 2013; 147: 536-9.

18 Zhu XM, Fang LH, Li YJ, Du GH. Endothelium-dependent and -independent relaxation induced by pinocembrin in rat aortic rings. Vasc Pharmacol 2007; 46: 160-5.

19 de Cunha GH, de Moraes MO, Fechine FV, Frota Bezerra FA, Silveira $\mathrm{ER}$, Canuto KM, et al. Vasorelaxant and antihypertensive effects of methanolic fraction of the essential oil of Alpinia zerumbet. Vasc Pharmacol 2013; 58: 337-45.

20 Fang JS, Wu P, Yang RY, Gao L, Li C, Wang D, et al. Inhibition of acetylcholinesterase by two genistein derivatives: kinetic analysis, molecular docking and molecular dynamics simulation. Acta Pharm
Sin B 2014; 4: 430-7.

21 Fang LH, Zhang YH, Ma JJ, Du GH, Ku BS, Yao HY, et al. Inhibitory effects of tetrandrine on the serum- and platelet-derived growth factorBB-induced proliferation of rat aortic smooth muscle cells through inhibition of cell cycle progression, DNA synthesis, ERK1/2 activation and c-fos expression. Atherosclerosis 2004; 174: 215-23.

22 Huo Y, Yi B, Chen M, Wang ND, Chen PG, Guo C, et al. Induction of Nur77 by hyperoside inhibits vascular smooth muscle cell proliferation and neointimal formation. Biochem Pharmacol 2014; 92: 590-8.

23 Jiang Q, Huang R, Cai S, Wang CL. Caldesmon regulates the motility of vascular smooth muscle cells by modulating the actin cytoskeleton stability. J Biomed Sci 2010; 17: 6.

24 Zhang TT, Sun L, Liu R, Zhang D, Lan X, Huang C, et al. A novel naturally occurring salicylic acid analogue acts as an anti-inflammatory agent by inhibiting nuclear factor-kappaB activity in RAW264.7 macrophages. Mol Pharm 2012; 9: 671-7.

25 Pellet-Many C, Frankel P, Evans IM, Herzog B, Junemann-Ramirez M, Zachary IC. Neuropilin-1 mediates PDGF stimulation of vascular smooth muscle cell migration and signalling via p130Cas. Biochem J 2011; 435: 609-18.

26 Park HS, Choi GH, Hahn S, Yoo YS, Lee JY, Lee T. Potential role of vascular smooth muscle cell-like progenitor cell therapy in the suppression of experimental abdominal aortic aneurysms. Biochem Biophys Res Commun 2013; 431: 326-31.

27 Chen L, Wang WY, Wang YP. Inhibitory effects of lithospermic acid on proliferation and migration of rat vascular smooth muscle cells. Acta Pharmacol Sin 2009; 30: 1245-52.

28 Guo R, Li WM, Liu BX, Li S, Zhang BC, Xu Y. Resveratrol protects vascular smooth muscle cells against high glucose-induced oxidative stress and cell proliferation in vitro. Med sci Monit basic Res 2014; 20: 82-92.

29 Hipolito UV, Rodrigues GJ, Lunardi CN, Bonaventura D, Ambrosio SR, de Oliveira AM, et al. Mechanisms underlying the vasorelaxant action of the pimarane ent-8(14),15-pimaradien-3beta-ol in the isolated rat aorta. Eur J Pharmacol 2009; 616: 183-91.

30 Osanai T, Tomita H, Kushibiki M, Yamada M, Tanaka M, Ashitate T, et al. Coupling factor 6 enhances Src-mediated responsiveness to angiotensin II in resistance arterioles and cells. Cardiovasc Res 2009; 81: 780-7.

31 Leung T, Chen XQ, Manser E, Lim L. The p160 RhoA-binding kinase ROK alpha is a member of a kinase family and is involved in the reorganization of the cytoskeleton. Mol Cell Biol 1996; 16: 5313-27.

32 Samain E, Bouillier H, Rucker-Martin C, Mazoit JX, Marty J, Renaud $\mathrm{JF}$, et al. Isoflurane alters angiotensin II-induced $\mathrm{Ca}^{2+}$ mobilization in aortic smooth muscle cells from hypertensive rats: implication of cytoskeleton. Anesthesiology 2002; 97: 642-51.

33 Haller H, Lindschau C, Erdmann B, Quass P, Luft FC. Effects of intracellular angiotensin II in vascular smooth muscle cells. Circ Res 1996; 79: 765-72.

34 Satoh K, Nigro P, Matoba T, O'Dell MR, Cui Z, Shi X, et al. Cyclophilin A enhances vascular oxidative stress and the development of angiotensin II-induced aortic aneurysms. Nat Med 2009; 15: 64956.

35 Gao P, Qian DH, Li W, Huang L. NPRA-mediated suppression of Ang II-induced ROS production contribute to the antiproliferative effects of B-type natriuretic peptide in VSMC. Mol Cell Biochem 2009; 324: 165-72.

36 Oh KS, Oh BK, Park CH, Seo HW, Kang NS, Lee JH, et al. Cardiovascular effects of a novel selective Rho kinase inhibitor, 2-(1H-indazole-5-yl)amino-4-methoxy-6-piperazino triazine (DW1865). Eur J Pharmacol 2013; 702: 218-26. 
37 Satoh K, Fukumoto Y, Shimokawa H. Rho-kinase: important new therapeutic target in cardiovascular diseases. Am J Physiol Heart Circ Physiol 2011; 301: H287-96.

38 Goodman KB, Cui H, Dowdell SE, Gaitanopoulos DE, Robert L, Sehon $\mathrm{CA}$, et al. Development of dihydropyridone indazole amides as selective Rho-kinase inhibitors. J Med Chem 2007; 50: 6-9.

39 Nagumo H, Sasaki Y, Ono Y, Okamoto H, Seto M, Takuwa Y. Rho kinase inhibitor HA-1077 prevents Rho-mediated myosin phosphatase inhibition in smooth muscle cells. Am J Physiol Cell Physiol 2000; 278: C57-65.

40 Montezano AC, Nguyen Dinh Cat A, Rios FJ, Touyz RM. Angiotensin II and vascular injury. Curr Hypertens Rrep 2014; 16: 431.

41 Do KH, Kim MS, Kim JH, Rhim BY, Lee WS, Kim CD, et al. Angiotensin II-induced aortic ring constriction is mediated by phosphatidylinositol 3-kinase/L-type calcium channel signaling pathway. Exp Mol Med 2009; 41: 569-76.

42 Touyz RM. The role of angiotensin II in regulating vascular structural and functional changes in hypertension. Curr Hypertens Rep 2003; 5: 155-64.

43 Cao X, Luo T, Luo X, Tang Z. Resveratrol prevents Ang II-induced hypertension via AMPK activation and RhoA/ROCK suppression in mice. Hypertens Res 2014; 37: 803-10.

44 Savoia C, Tabet F, Yao G, Schiffrin EL, Touyz RM. Negative regulation of RhoA/Rho kinase by angiotensin II type 2 receptor in vascular smooth muscle cells: role in angiotensin II-induced vasodilation in stroke-prone spontaneously hypertensive rats. J Hypertens 2005; 23 : 1037-45.

45 Chiu WC, Juang JM, Chang SN, Wu CK, Tsai CT, Tseng YZ, et al. Angiotensin II regulates the LARG/RhoA/MYPT1 axis in rat vascular smooth muscle in vitro. Acta Pharmacol Sin 2012; 33: 1502-10.

46 Wang Y, Wang W, Wang Q, Wu J, Xu J, Wu X. $\left[\mathrm{Ca}^{2+}\right]_{\mathrm{i}}$ and PKC- $\alpha$ are involved in the inhibitory effects of $\mathrm{Ib}$, a novel nonpeptide angiotensin
II subtype $\mathrm{AT}_{1}$ receptor antagonist, on angiotensin II-induced vascular contraction in vitro. Biochem Biophysi Res Commun 2007; 364: 118-23.

47 Chi YH, Lee JH, Kim JH, Tan HK, Kim SL, Lee JY, et al. Pharmacological characterization of BR-A-657, a highly potent nonpeptide angiotensin II receptor antagonist. Biol Pharm Bull 2013; 36: 1208-15.

48 Kramer HJ, Mensikova V, Backer A, Meyer-Lehnert H, Gonick HC. Interaction of dimercaptosuccinic acid (DMSA) with angiotensin II on calcium mobilization in vascular smooth muscle cells. Biochem Pharmacol 2003; 65: 1741-6.

49 Touyz RM, Schiffrin EL. Signal transduction mechanisms mediating the physiological and pathophysiological actions of angiotensin II in vascular smooth muscle cells. Pharmacol Rev 2000; 52: 639-72.

50 Berridge MJ. Smooth muscle cell calcium activation mechanisms. J Physiol 2008; 586: 5047-61.

51 Zhang Z, Li M, Lu R, Alioua A, Stefani E, Toro L. The angiotensin II type 1 receptor $\left(\mathrm{AT}_{1} \mathrm{R}\right)$ closely interacts with large conductance voltage- and $\mathrm{Ca}^{2+}$-activated $\mathrm{K}^{+}(\mathrm{BK})$ channels and inhibits their activity independent of G-protein activation. J Biol Chem 2014; 289: 25678-89.

52 Konior A, Schramm A, Czesnikiewicz-Guzik M, Guzik TJ. NADPH oxidases in vascular pathology. Antioxid Redox Signal 2014; 20 : 2794-814.

53 Ishida T, Ishida M, Suero J, Takahashi M, Berk BC. Agonist-stimulated cytoskeletal reorganization and signal transduction at focal adhesions in vascular smooth muscle cells require c-Src. J Clin Invest 1999; 103: 789-97.

54 Julian L, Olson MF. Rho-associated coiled-coil containing kinases (ROCK): structure, regulation, and functions. Small GTPases 2014; 5: e29846.

55 Custodis F, Eberl M, Kilter H, Bohm M, Laufs U. Association of RhoGDlalpha with Rac1 GTPase mediates free radical production during myocardial hypertrophy. Cardiovasc Res 2006; 71: 342-51. 